\title{
Chinese-Spanish Immigrant Child Performance on Chinese Language Tests: A Case Study on Chinese-Spanish Children
}

\author{
Yiyun Ou \\ Faculty of Humanities, University of Malaga, Spain
}

Copyright $\mathrm{C} 2019$ by authors, all rights reserved. Authors agree that this article remains permanently open access under the terms of the Creative Commons Attribution License 4.0 International License

\begin{abstract}
Research on Chinese-speaking communities in recent years has accompanied growing interest in language acquisition and usage in Chinese immigrant children. Second-generation Chinese immigrants must navigate a highly complex linguistic environment rife with factors that affect their language proficiency. Overseas, Chinese children face greater difficulties in learning Chinese and show generally low Chinese proficiency compared to their non-immigrating counterparts. What exactly are the difficulties in the process of their Chinese learning? How can their Chinese language proficiency be precisely defined? What are the external and internal factors that influence their language skills? To solve these questions, we assessed 80 Chinese children ranging from 7-9 years of age in Malaga City, Spain, by issuing questionnaires, interviews, and language tests designed to reveal the relationship between their language proficiency and living conditions. Factors such as family environment, parents' occupation, parents' education, and language attitude and motivation are taken into consideration as crucial factors, which affect language proficiency. We also distributed a language test to 80 Chinese students at South Lake Primary School in Hubei Province to compare their language proficiency with that of the Spanish immigrant children overall, and to identify specific points of weakness. A combination of quantitative and qualitative approaches was used in the data analysis.
\end{abstract}

Keywords Sociolinguistics, Chinese Language Community, Bilingual Children, Language Proficiency

\section{Introduction}

Bilingualism is a linguistic phenomenon in which an individual speaks two (or more) languages to communicate based on different situations encountered in daily life. In this study, we focus on Chinese children with Chinese-born parents whose families have immigrated to Spain. Within this linguistic environment, the children are indeed bilingual; they speak both Chinese and Spanish in certain contexts. You and Zou (2009: 55) divided bilinguals into seven classifications: receptive bilingual, productive bilingual, symmetrical bilingual, asymmetrical bilingual, equilingual, ambilingual, and vertical bilingual. You (2009: 55) affirmed that only those who have equal proficiency across two languages, with respective fluency to monolinguals in both languages, can be considered equilinguals.

Previous studies have shown that the development of bilingualism in Chinese immigrant children is not balanced (Kang 2015; Wang et al. 2005; Wang 2010). It is difficult for Chinese bilingual children born abroad to reach the native-speaker standards of Chinese monolinguals (Wang, 2009). Their second-language grammar and vocabulary development is also slower than that of monolinguals (Peng, 2005). Gregory (1993: 56) pointed out that such immigrant children gradually lose their very sense of Chinese cultural identity as their Chinese language skills diminish over time. Sheng (2012) asserts, similarly, that Chinese language abilities degrade as Chinese immigrant children grow up overseas.

Studies have shown that Chinese immigrant children are less proficient in Chinese language than monolingual children. Exactly how wide is the disparity between these groups of children in their level of language ability? Can immigrant children perform as well on Chinese language tests as their native Chinese counterparts? The author is a Chinese teacher who has been working with immigrant children in Spain for several years; the children have consistently shown relatively poor students proficiency in the Chinese language, both oral and written. So, what are the main factors that determine their language proficiency? The present investigation was conducted in order to provide empirically sound, comprehensive answers to 
these questions.

The majority of extant studies on the Chinese immigrant child's language characteristics center on English-speaking countries (Sheng, 2012; Huang, 2013; Li, 1994; Peng, 2006; Wang, 2010), so we selected a non-English-speaking country, Spain, to conduct our investigation. According to figures presented by Ioé (2005: 12), Chinese immigrants in Spain are concentrated in autonomous communities of the Iberian Peninsula and in Mediterranean provinces from Girona to Malaga; Malaga ranks fifth in its proportion of immigrants after Madrid, Barcelona, Alicante, and Valencia. According to our research, more than $70 \%$ of Chinese immigrants in Malaga came from Qingtian County, Zhejiang Province, as supported by data from Gladys (2003: 225). To this effect, Chinese children in Malaga represent a typical example of this group throughout Spain. We hope this research provides workable resources to mitigate the relative scarcity of studies on language acquisition and usage in Chinese-Spanish children.

\section{Methodology}

This research follows a case-study design with in-depth analysis of the linguistic conditions of Chinese children in Spain. The mixed method, which integrates quantitative and qualitative data has been utilized in many previous linguistics studies (Creswell 2003; Dörnyei 2007; Itkonen 1979; Phakiti 2015). We conducted the present study in two parts to gather data via both qualitative and quantitative methods: 1) a questionnaire consisting of 24 questions for the purpose of gathering information about the research participants, and 2) a Chinese language test to assess the participants' language acumen.

\subsection{Participants}

The participants in this study are immigrant students 7-9 years of age at the Huajiao School, a weekend language school that recruits Chinese children. Chinese classes are provided on Saturdays and Sundays as the children attend Spanish school on weekdays. Of our 80 participants, 55 are boys and 25 are girls.

We compared language proficiency between the Chinese-Spanish immigrant children (CIC) and Chinese native children (CNC). As Hulstijn (2015, 139) recommends, "to compare bilinguals' performance to the performance of native-speaker reference groups" can reveal useful information regarding language proficiency in the bilingual population. We chose 80 second-graders from the South Lake Primary School to evaluate the real language proficiency of $\mathrm{CNC}$; South Lake has medium-average rankings across all primary schools in Wuhan City, Hubei Province, so its students have academic performance representative of the local children.

\subsection{Questionnaire (Anexo 1)}

The questionnaire is a method used to gather information about a certain participant population by asking them questions. In this study, questionnaires were distributed in Spanish to the CIC participants to ensure efficacy due to their low level of Chinese language skill. As per the sociolinguistics perspective of this study, we also sought to ensure that relevant social factors were taken into consideration in regards to their relationship to linguistic conditions; they include age, date of birth, sex, address, place of birth, place of parents' birth, length of time spent learning Spanish and Chinese, self-reported identity ("Chinese" or "Spanish"), parents' education, parents' occupation, composition of family members, preschool education, type of first language, self-assessment of language proficiency, assessment of family members' language proficiency, assessment of the difficulty of learning different languages, interest in languages, and frequency of use of each language in distinct context (among other minor factors as discussed below).

\subsection{Language Test (Anexo 2)}

We distributed a language test to evaluate the language proficiency of CIC and CNC. It is a final Chinese language exam distributed to Grade Two students at South Lake Primary School which has a maximum score of 100 points. The test design includes both discrete-point and integrative testing methods (Oller, 1979); it assesses not only listening, reading, and writing skills combined with the various units of language such as phonology, morphology, lexicon, and syntax, but also includes cloze tests and dictations. The test was divided into six exercises. The first is a Pinyin exercise $^{1}$, which requires the children to transcribe dictations in pinyin. The second is similar, but the dictations are to be transcribed in Chinese characters. The third part tests vocabulary, where children are instructed to write compound words for separate Chinese characters. The fourth asks the children to create a complete sentence to support a given word using correct grammar. The fifth assesses reading compression mixed with a cloze test, where the children answer questions after reading a given text with several words deleted. The sixth and final part is a writing exercise wherein the children compose a "short story" related to a given series of photographs.

The hypothesis of this study is that there is explicit the difference in Chinese language ability between CIC and CNC. The study objectives based on this hypothesis are:

1. To compare and analyze the results of each test exercise between CIC and CNC participants;

2. To explore relevant factors which influence CIC Chinese learning (e.g., self-identification, interest, and parents' education level).

1 Pinyin: The official phonetic alphabet system of Chinese Mandarin. 
All data were analyzed in the software Eviews 10 for Windows.

\section{Results and Discussion}

In verifying our hypotheses, we first assayed the inequality in test performance between CIC and CNC.

Table 1. Test for Grade Equality between CIC and CNC

\begin{tabular}{lrrr}
\hline Method & df & Value & Probability \\
\hline t-test & 158 & 9.772862 & 0.0000 \\
\hline $\begin{array}{l}\text { Satterthwaite-Welch } \\
\text {-test* }\end{array}$ & 136.5363 & 9.772862 & 0.0000 \\
\hline Anova F-test & $(1,158)$ & 95.50882 & 0.0000 \\
\hline Welch F-test* & $(1,136.536)$ & 95.50882 & 0.0000 \\
\hline
\end{tabular}

All contrast statistics show p-values below 5\%, therefore, there is sufficient empirical evidence to reject the null hypothesis that there is no difference in CIC and CNC scores. So, how wide is the gap between them?

Among CIC, 9 children achieved a full score of 100 points, 53 children (66\%) achieved more than 90 points, 20 children (25\%) achieved a score between 80 and 90, 4 children (5\%) obtained a score between 70 and 80,2 children obtained a score between 60 and 70 , and 1 child $(1.25 \%)$ achieved a score less than 60 . In other words, $81 \%$ of the native Chinese children made high scores (more than 80 points) and only 1 child failed the exam. The average score across the $80 \mathrm{CNC}$ participants is 91.23 .

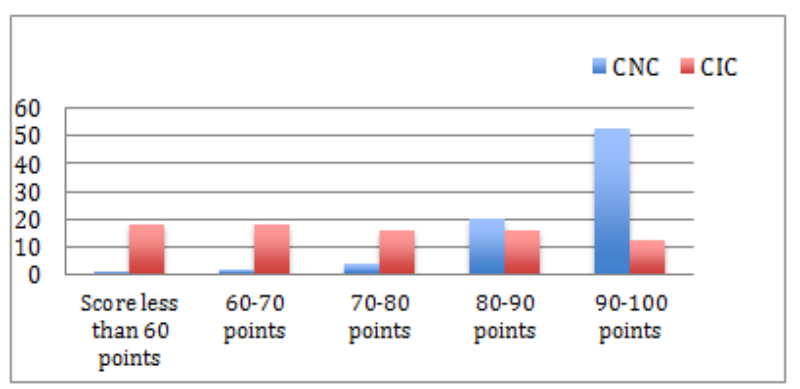

Figure 1. Comparison between $\mathrm{CIC}$ and $\mathrm{CNC}$ Scores

The grades achieved by CIC participants are much lower than those of their CNC counterparts. Among the CIC, though 12 of them (15\%) achieved a score over 90 points, 16 children $(20 \%)$ obtained a score between 80 and 90,16 $(20 \%)$ children achieved a score between 70 and 80,18 children obtained between 60 and 70 , and 18 children (23\%) achieved a score below 60 , i.e., failed the exam. The average score for CIC students is 72.89 , which is 18.34 points lower than the $\mathrm{CNC}$ average.

\subsection{CIC Difficulties in Learning Chinese}

Our CNC participants performed much better on the language test than the CIC participants. We sought to determine why their scores differed so significantly in terms of specific weaknesses in the CIC's Chinese language skills as-expressed in their scores on each exercise.

The largest gap between the two groups exists in Exercise 6 (writing) (5.4 points), and the second-largest in Exercise 5 (4.0375 points). The difference in Exercise 4 was 3.2125 points, in Exercise 3 was 3.0625 points, and in Exercise 2 was 2.2. The smallest difference between CIC and $\mathrm{CNC}$ was 0.6875 points in Exercise 1, the Pinyin exercise.

\subsubsection{Pinyin}

The CIC and CNC participants performed fairly similarly on the Pinyin exercise. Pinyin is the Romanization of Chinese characters based on their pronunciation, where words are written in Latin letters with tones as a useful tool to pronounce Chinese characters. The Spanish language and Pinyin share the same Latin letters, so Chinese-Spanish children tend to accept the alphabet system without great difficulty; this helped them to perform well on the Pinyin exercise. That being said, language transfer can also be negative. Pinyin differs from other Romanizations in several aspects that may have been confusing for CIC in filling out our test. For example, the lip consonant " $p$ " is not aspirated in Spanish while in Pinyin, it is. Sixteen CIC children confused "b" with "p", 19 confused "d" with "t", 12 confused "j" with "h", 8 confused "yan" and "yien", and as many as 63 children had difficulty in distinguishing the nasal velar "-ng" and the nasal alveolar "-n".

Table 2. Score Gaps by Exercise between CIC and CNC

\begin{tabular}{|c|c|c|c|c|c|c|c|}
\hline Exercise & Total & 1 & 2 & 3 & 4 & 5 & 6 \\
\hline Test items & & Pinyin & Characters & Vocabulary & Sentence & $\begin{array}{c}\text { Reading } \\
\text { comprehension }\end{array}$ & Writing \\
\hline $\begin{array}{c}\text { Score gaps } \\
\text { between CIC and } \\
\text { CNC }\end{array}$ & 18,4875 & 0,6875 & 2,2 & 3,0625 & 3,2125 & 4,0375 & 5,4 \\
\hline
\end{tabular}


One of the reasons our CIC participants made mistakes in pronouncing "-ng" and "- $n$ " is the influence of the dialect Qingtian, which their parents speak at home and has influenced their acquisition of the Chinese language. In the Qingtian dialect, the nasal velar "-ng" and the nasal alveolar "-n" belong to the same linguistic phoneme; in Pinyin, they are two distinct phonemes. CIC children had difficulty in generally distinguishing the "-ng" and "-n" phonemes in Pinyin, for example, tending to write "heng" for "hen", "feng" for "fen", and "neng" for "nen".

Our CIC also appear to struggle with to the four distinct tones of the Chinese Mandarin language. Consider the vowel "a", which has tones ā, á, ă, and à. We found that the CIC struggle in particular with the second and third tones. The second tone progresses in pitch from low to high, while the third falls from high to low and then rises again; the two tones sound very similar even to native speakers of the intonation. Among the $80 \mathrm{CIC}, 16$ were unable to distinguish these tones clearly and 9 pronounced the four tones with a foreign accent. This phenomenon is rare in native Chinese children. According to Yuan, a Chinese teacher at Nanhu Primary School, "None of the students in [my] class has this kind of problem, since almost all of them know how to pronounce the correct tone of the characters".

\subsubsection{Characters}

CIC participants obtained an average score of 16.1625 on Exercise 2, which is 2.2 points lower than the CNC. Generally, regardless of whether the children live in China or in Spain, characters represent great difficulty in the first stage of Chinese language acquisition. According to the dictionary Zhong hua Zi hai (1994), there are 85,568 characters in total of which 3,500 are most frequently used. Chinese characters are composed of different strokes which children learn a set of rules in order to write. Each stroke of a character must be written in an established order; generally, the horizontal strokes are drawn first and the vertical ones next, from left to right and from top to bottom. It is easy for Chinese children to make mistakes such as adding an extraneous stroke or missing one stroke in a character.

Similar characters like “已” and “己” or “大” and “太” seemed especially confusing to our CIC participants. Among the $80 \mathrm{CIC}, 64$ of them (80\%) made mistakes on Exercise 2. Some CIC appear to have memorized characters in the form of an image and write them similarly to drawing a picture, rather than following the rules of writing. However, writing characters without the established rules increases the probability of mistakes. Memorizing thousands of characters is very challenging and demands a great deal of practice. Children native to China are immersed in a linguistic environment that includes these characters, while Chinese-Spanish children encounter them only in Chinese class, or perhaps on a signboard at a local Chinese restaurant. Without the language context and visual environment, the CIC simply are not given the same opportunity to practice reading and writing characters and thus tend to struggle with them more than their CNC counterparts.

\subsubsection{Vocabulary}

In the vocabulary exercise, CIC obtained 3.0625 points less on average than $\mathrm{CNC}$. In this exercise, the children were asked to compose two compound words from a list of 20 Chinese characters. As many as 55 CIC children left several blanks in this exercise while only $11 \mathrm{CNC}$ left any blanks. Some CIC explained that they "couldn't remember how to write the correct word even though [they knew] the word". In general, when we asked them questions about vocabulary, they responded verbally much quicker than they were able to respond in writing.

\subsubsection{Reading Comprehension}

Next, the students were asked to answer questions about a given text after reading it to test their comprehension. Again, the CIC showed an obvious gap in performance compared to the CNC participants. Some indicated they could not understand the intent of the questions although they understood the general meaning of the article; some affirmed that they could answer the questions but did not know how to compose a written response due to their inability to write the characters. The written answers given by the CIC children contained an abundance of unclear and incoherent sentences alongside significant grammatical errors.

\subsubsection{Writing}

Exercises 4 and 6 were designed to evaluate the children's Chinese writing ability. In Exercise 6, CIC showed a difference of 5.4 points compared to $\mathrm{CNC} ; 81 \%$ of CIC participants made errors in grammar, $78 \%$ used incorrect vocabulary words, and 55\% utilized Spanish syntax, for example, they placed the adverbial modifier behind the predicate (while in Chinese they are placed in the opposite order):
a. * 我 看书
Yo leo libros
在 家里。
read books at home.)
The correct sentence in Chinese is:

$\begin{array}{llc}\text { 我 } & \text { 在家里 } & \text { 看书。 } \\ \text { Yo } & \text { en casa } & \text { leo libros. } \\ (\mathrm{I} & \text { at home } & \text { read books.) }\end{array}$

The misuse of conjunction 和 (“and" in English) was also common in the CIC's written sentences, for example: c. *我喜欢看电视, 和我妈妈也喜欢看电视。

A mí me gusta ver la tele y a mi madre le gusta también. (I like watching TV and my mother likes it, too.)

In Spanish, the conjunction "and" is necessary to combine the two clauses while in Chinese, the conjunction "and" between two clauses is replaced by a comma. This mistake was present in $41 \%$ of the CIC test results. 
Table 3. Data Correlation

\begin{tabular}{crrrrr}
\hline Variable & Coefficient & Std. Error & t-Statistic & Prob. \\
\hline C & 13.02795 & 22.61762 & 0.576009 & 0.5667 \\
\hline Occupation of Parents & 9.048882 & 0.918571 & -2.230511 & $* * 0.0293$ \\
\hline Gender & -0.553797 & 2.543536 & -0.217727 & 0.8283 \\
\hline Self-language Evaluation & -3.441365 & 1.914407 & -1.797614 & 0.0770 \\
\hline Parents' Chinese level & 0.332504 & 2.046437 & 0.162480 & 0.8714 \\
\hline Brothers and Sisters' Chinese level & -0.750361 & 3.940646 & -0.190416 & 0.8496 \\
\hline First Language & -6.096316 & 4.250312 & -1.434322 & 0.1564 \\
\hline Education level of Parents & 14.16779 & 3.779206 & 3.748880 & $* * * 0.0004$ \\
\hline f-identification & 11.44154 & 4.499334 & 2.542942 & $* * 0.0135$ \\
\hline Age & 1.595373 & 2.605565 & 0.612295 & 0.5425 \\
\hline Difficulty Assessment of Chinese Language & 0.741618 & 4.446428 & 0.166790 & 0.8681 \\
\hline Interest in Learning Chinese & 4.294676 & 1.421624 & 3.020965 & $* * * 0.0036$ \\
\hline
\end{tabular}

Indeed, the CIC's Chinese language skills appear to be influenced by negative transfer of the Spanish language. Very few were able to write in a "Chinese way", even if they effectively understood the question and answer at hand - they tended to prefer Pinyin rather than Chinese characters in expressing themselves through writing. Writing correct Chinese characters rather than Pinyin is an essential skill at Chinese school. The CIC, to this effect, presented a great disadvantage in writing abilities compared to the CNC.

\subsection{Internal and External Factors which Impact CIC Chinese-learning}

Although CIC showed an inferior performance in the language test overall, $35 \%$ of them still made scores over 80 points. We categorized all the items collected from the questionnaire combined with the total scores to isolate factors that may influence individual test performance.

All "Prob" values below 0.05 indicate sufficient empirical evidence against the null hypothesis (any coefficients equal to zero indicate irrelevant variables). The results indicate that four variables are highly correlated to CIC scores $(p<0.05)$ : parents' occupation $(p=0.0293)$, parents' education level $(p=0.0004)$, self-identification $(p=0.0004)$, and interest $(p=0.0036)$. Among the four relevant variables, the interest and the self-identity are internal factors while the occupation and education of parents are external. Factors such as gender, age, and difficulty of language assessment showed no obvious relevance to $\mathrm{CIC}$ test performance.

\subsubsection{Parents' Education}

The variable most relevant to CIC test performance is the parents' level of education $(p=0.0004)$. Children of more-educated parents scored 14.167 points more than children of parents with lower levels of education. Previous researchers have also strongly asserted that external factors are determinants of language acquisition (Bybee, 2001, Tomasello, 2003).

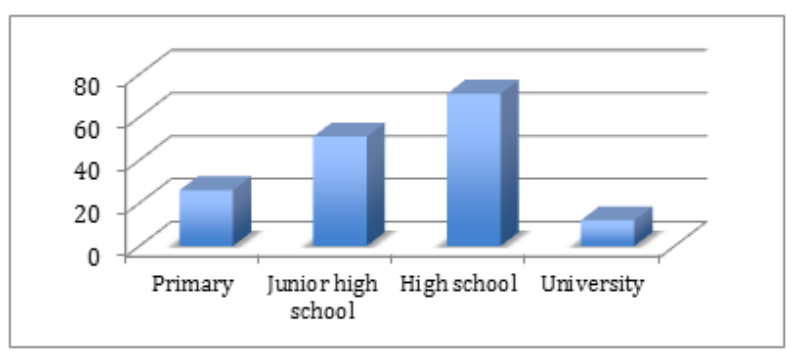

Figure 2: Chinese Parents' Education Level

As shown above, only $12(8 \%)$ of our participants have parents with university-level education; the majority, 71 (44\%) of them, have parents holding only high school diplomas. The parents of $51(32 \%)$ of them graduated from junior high school, and the parents of $26(16 \%)$ only graduated from primary school. Parents with higher levels of education may attach more importance to their child's Chinese-learning than the parents who are less educated. The results of our questionnaire show that parents with university diplomas spend 2-4 hours per week tutoring their children, while parents with primary school educations indicated that they do not have the time or ability to help their children study. Children in families with more educated parents receive more educational input at home (Ellis, 2002; Lieven \& Tomasello, 2008). Family environment plays a crucial role in the CIC's Chinese language performance.

\subsubsection{Parents' Occupation}

Another external factor that affects the CIC's language acquisition is their parents' occupation $(p=0.0293)$. Our results indicate that children whose parents are engaged in large-scale enterprise scored 9.04 points higher that the children whose parents work in small retail stores. Occupation reflects the economic status of the family, so 
our results provide evidence for differences in the language competence of children from high social economic status (SES) and low-SES backgrounds (Labov, 1969; Bernstein 1973; Ginsborg, 2006). We found that $89 \%$ of the parents of CIC children are self-employed in enterprises such as wholesale stores, grocery stores, and restaurants. To analyze the data more efficiently, we divided occupations into five categories based on the scale of the business and the general income in ascending order. The figure below shows the relation between parents' occupation and CIC test performance.

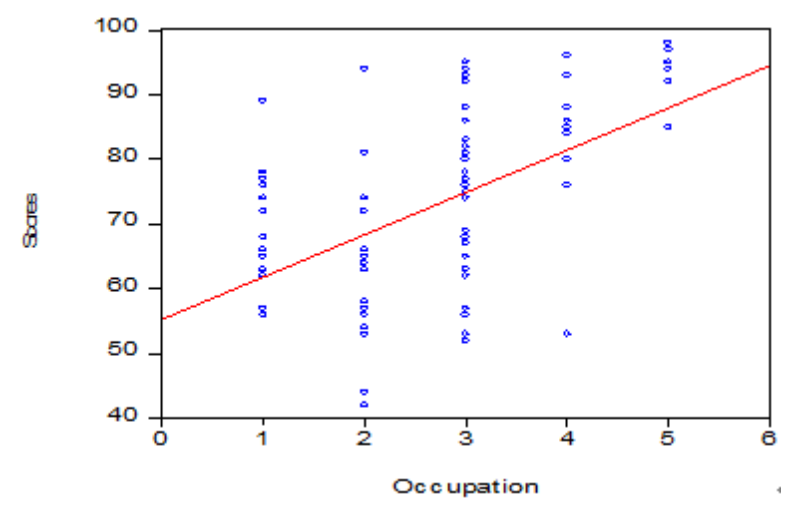

Figure 3. Parents' Occupation ${ }^{2}$ and Child's Scores

Children of low-SES families obtained scores of 40-90 points, most in the range 52-80. Children of high-SES families achieved scores from 75 to 100 and mostly around 80. Though Occupation 5 (teachers and officers) have lower SES than Occupation 4 (large-scale wholesalers), their children achieved better performance in the language test (scores $>85$ points). Our results show that CIC parents' education has a stronger impact on language performance than their parents' occupation does.

The parents of many of our participants are employed in Chinese businesses. They tend to rotate on duty and are stationed in their shops from early morning to late in the evening. As is known in Spain, Chinese stores run on a busier schedule than local Spanish stores, many from 10 a.m. to 10 p.m. and seven days per week - this is another likely objective reason why Chinese parents were unable to spend time tutoring their children and are relatively uninvolved in their children's education.

\subsubsection{Language Attitude and Motivation}

Many previous researchers have explored the role of attitude and motivation in language learning (Crookes \& Schmidt, 1989; Dornyei, 1990; Lambert, 1955; Lukmani, 1972; Gardner and Moorcroft, 1985;). Gardner (1985) operationalized motivation by means of the Attitude and Motivation Index, a self-report in which participants respond to Likert-style items on various aspects of motivational orientation including attitudes toward the target language, its culture, and its speakers (Skehan 199: 281). Likert-type statements can be used to measure intentions, beliefs, values, and attitudes toward learning languages (Dornyei, 1990: 10). Gottfried (1985, 1990) affirmed that interest is predictive of specific motivational orientation. We found that CIC participants are not strongly motivated to learn Chinese.

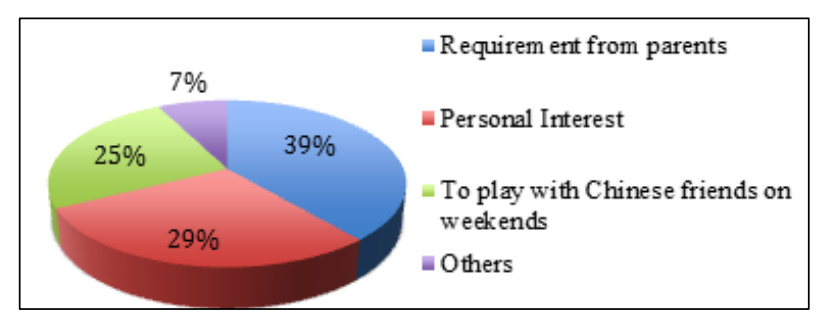

Figure 4. Reasons to Learn Chinese at Huajiao Chinese Language School

Only $29 \%$ of CIC reported personal interest in learning about Chinese language and culture. They stated that they enjoy watching Chinese TV programs and even reading Chinese storybooks. The majority, $39 \%$ of them, indicated that learning Chinese at weekend school is a requirement of their parents - they stated that they would prefer to stay home and relax on weekends. Twenty present of the CIC indicated that they attend Chinese school to play with their friends who are also enrolled in the school during weekends. The remaining $7 \%$ of them were not clear about the reason, so we marked their answer as "other".

As mentioned above, children who were interested in the Chinese language achieved 4.16 more points on average than those who were not interested. Moreover, according to our survey, $91 \%$ of the CIC consider Chinese to be the most difficult language among Chinese, Spanish, and English. Sixty-five present of them consider Spanish and English "more beautiful" than Chinese to pronounce. In effect, most of Chinese-Spanish children we tested hold a relatively negative attitude toward the Chinese language.

Although a negative attitude is an internal psychological factor, it can be affected by external factors such as the sociolinguistic environment, language policy, and language community status. From the sociolinguistics perspective, Chinese Mandarin is considered a "lower-level language" compared to the official language in Malaga, Spanish. Chinese language has limited functions restricted to the city's Chinese language communities. The children we assessed tend to use more Spanish than Chinese, as evidenced by the frequency of their Chinese language use across their social circles. 
Table 4. Frequency of Language Use Across the Social Circle

\begin{tabular}{|c|c|c|c|}
\hline $\begin{array}{c}\text { Social Circle } \\
\text { Member }\end{array}$ & Spanish & $\begin{array}{c}\text { Chinese } \\
\text { Mandarin }\end{array}$ & Others \\
\hline Father & 1.2 & 2.2 & 0.2 \\
\hline Mother & 1.2 & 2.2 & 0.2 \\
\hline Siblings & 2.8 & 0.9 & 0.8 \\
\hline Grandparents & 0.1 & 0.4 & 0.2 \\
\hline Chinese Friends & 2.8 & 1.0 & 0.8 \\
\hline Spanish Friends & 3 & 0 & 0.8 \\
\hline
\end{tabular}

Our results indicate that CIC participants use Chinese more than Spanish when speaking to their parents, but use Spanish more with their siblings and friends. We found that $87 \%$ of them believe that they speak Spanish better than they speak Chinese. From our observation, most of them speak Spanish fluently and confidently but express anxiety when speaking Chinese (especially in class).

The quality of Chinese teaching in Malaga merits consideration as a factor that impacts the CIC's interest in learning Chinese. According to our survey, there are four large Chinese language schools in Malaga Center with around 700 Chinese students in total. The first Chinese language school is the Chinese Institute of Malaga, which was founded in 2009; in short, the Chinese education system has a brief history and much room for further development. As weekend schools, Chinese language schools tend to hire part-time teachers under less strict requirements than full-time teachers. College students at the University of Malaga are not uncommonly employed at such Chinese language schools. We interviewed several young teachers who are also Malaga University students: eight of them said they had no experience teaching Chinese prior to their current station and nine said that teaching Chinese to children is an "easy job" - they simply read books to the children, gave brief instructions on writing Chinese characters, and distributed homework. Learning resources such as Chinese books, Chinese cultural activities, media, and videos are relatively inadequate to expose Chinese children to an authentic linguistic environment and may impact their attitudes toward the Chinese language.

\subsubsection{Language and Identity}

Identity is also of interest to researchers in regards to its relation to motivation for language-learning. According to Norton, "speech, speakers, and social relationships are inseparable. The question 'Who am I' reflects to how people understand their relationship to the world, how that relationship is constructed across time and space, and how people understand their possibilities for the future" (1997: 410). Norton (1997: 413) also considers the relationship between language and identity to be not only abstract and theoretical but also to have important consequences for positive and productive language-learning and teaching. The results of our survey show that 35 of the CIC (44\%) consider themselves Chinese, 29 (36\%) consider themselves as Spanish, and 16 of them (20\%) are "confused" about their self-identity. It is worth noting that children with self-reported Chinese identity performed better on average on the Chinese language test than children who self-reported Spanish identity.

As second-generation immigrants to Spain, CIC children are much more familiar with Spanish culture and ideology than Chinese. They participate in various activities in their daily lives while receiving knowledge from local Spanish schools, watching Spanish TV programs (e.g., football games), and celebrating Spanish festivals with local Spanish people. They have integrated themselves into their host country without the same difficulties that their parents have, as they are able to communicate fluently in Spanish. This process creates a series of psychological conflicts in Chinese-Spanish children. Differences in their physical appearance attributable to their ethnicity make them easily distinguishable from other Spanish children, for example, which may cause native Spanish individuals consider them to be "foreigners".

In referring to the Chinese country and its culture, 41 of the CIC affirmed that China is the hometown of their parents. Further, 38\% of them have never been to China though $62 \%$ of them said they had gone to China on vacations with their families. One child described his experience in China as:

During [those] days, I got up very early, [ate] breakfast, lunch, and dinner very early. I didn't [have much of] a good appetite... I didn't know what to do every day and time passed so slowly. I talked to the native Chinese children and every time I spoke Chinese, they laughed at me, which made me uneasy. I hoped return to Spain soon.

Of the children who self-reported "Chinese identity", most also suggested that they had been implanted with the concept of their Chinese descent by their parents. Their first-generation immigrant parents have a stronger Chinese identity. We assayed 160 parents of the CIC, $81 \%$ of whom emphasized that they would "never abandon their Chinese identity" and $37 \%$ of whom said it is possible that one day they will return to China to live.

Complications in the Chinese-Spanish immigrant child's self-identity cause psychological and social conflicts within him or her, which affect his or her attitudes towards languages. As the immigrants' population is continually more deeply ingrained within the local society, and over time, the use of language by Chinese immigrants is expected to shift.

\section{Conclusions}

The results of this study altogether indicate that Chinese-Spanish immigrant children do not perform as well in Chinese language examinations compared to native Chinese children. They appear to encounter more 
difficulties in writing and reading comprehension in particular, but have a smaller performance gap in Pinyin expressions. In addition to the impact of Spanish language transfer, a series of internal and external factors are strongly correlated with their individual differences in test performance. Children of parents with higher education levels and economic statuses achieved performed better on the Chinese test, as did children who are more interested in Chinese language and/or identify themselves as Chinese. The linguistic environment and socioeconomic characteristics of the Chinese communities in Malaga also have significant influence on the
Chinese-Spanish children's attitudes toward the Chinese language. Fractured self-identities and apparent conflicts between the two cultures bring Chinese children in Spain certain difficulties in language-learning.

The survey deployed in this study provides preliminary information regarding Chinese bilinguals' language proficiency and its influencing factors. However, it was not without limitations. Engaging a larger number of participants and expanding the research to more areas may yield more accurate conclusions. We suggest further empirical research on the language acquisition of Chinese bilingual children to support the results presented here.

\section{Questionnaire (English Version)}

Date:

$$
\text { Gender: }
$$$$
\text { Male/ }
$$

Female

Date of birth:

Course:

Address:

1. You are:

a) Spanish

b) Chinese

Name of your town or city:

2. Town or city in which you were born:

3. City and province where they were born

a) your father:

b) your mother

4. In which year did your parents arrive in Spain?

5. Education of your father:

a) primary

b) secondary

c) university

6. Education of your mother:

a) primary

b) secondary

c) university

7. Profession of your father:

a) employee

b) businessman

c) teacher

d) doctor

e) others:

8. Profession of your mother:

a) employee

b) businesswoman

c) teacher

d) doctor

e) others:
a) restaurant
b) clothing store
c) supermarket
d) grocery store
e) others:

10 . Who live with you in your house?
a) father
b) mother
c) brother
d) sister
e) grandpa

f) grandma

g) uncle

h) aunt

g) others:

11. Your brother was born in the year

Your first language is:
a) Spanish
b) Chinese mandarin
c) Chinese dialect
d) English
e) others:

13. Who speaks the best Spanish?
a) you
b) your brother
c) your sister
d) your mother
e) your father

14. Who speaks the best Chinese?
a) you
b) your brother
c) your sister
d) your mother
e) your father 
15. Which language are you most interested in?
a) Spanish
b) Chinese mandarin
c) Chinese dialect
d) English
e) others:

16. Which language do you find most difficult??
a) Spanish
b) Chinese mandarin
c) Chinese dialect
d) English
e) others:

17. Do you think you speak Spanish the same as your Spanish colleagues?
a) yes, completely the same
b) a little different
c) no, completely different

18. How old were you when you started studying Chinese at school?

19. How old were you when you started studying Spanish at school?

20. Did you go to a Chinese kindergarten before primary school?
a) yes
b) no

21. Did you go to a Spanish kindergarten before primary school?

a) yes

b) no

22. Mark with a cross the languages you speak

\begin{tabular}{|l|l|l|l|l|l|}
\hline & Spanish & $\begin{array}{l}\text { Chinese } \\
\text { Mandarin }\end{array}$ & $\begin{array}{l}\text { Chinese dialect (Dialect } \\
\text { Qingtian) }\end{array}$ & English & Others: \\
\hline You & & & & & \\
\hline Your father & & & & & \\
\hline Your mother & & & & & \\
\hline $\begin{array}{l}\text { Your brothers and } \\
\text { sisters }\end{array}$ & & & & & \\
\hline Your grandparents & & & & & \\
\hline Others: & & & & & \\
\hline
\end{tabular}

23. Mark with a cross the language you use when you talk to these people

\begin{tabular}{|l|l|l|l|l|l|}
\hline & Spanish & $\begin{array}{l}\text { Chinese } \\
\text { Mandarin }\end{array}$ & $\begin{array}{l}\text { Chinese dialect (Dialect } \\
\text { Qingtian) }\end{array}$ & English & Others_ \\
\hline With your father & & & & & \\
\hline With your mother & & & & & \\
\hline $\begin{array}{l}\text { With your brothers and } \\
\text { sisters }\end{array}$ & & & & & \\
\hline With your grandparents & & & & & \\
\hline $\begin{array}{l}\text { With your Chinese } \\
\text { colleagues }\end{array}$ & & & & & \\
\hline $\begin{array}{l}\text { With your Spanish } \\
\text { colleagues }\end{array}$ & & & & & \\
\hline With your neighbors & & & & \\
\hline
\end{tabular}

24. Mark with a cross the language that speaks the best each person

\begin{tabular}{|l|l|l|l|l|l|}
\hline & Spanish & $\begin{array}{l}\text { Chinese } \\
\text { Mandarin }\end{array}$ & $\begin{array}{l}\text { Chinese dialect (Dialect } \\
\text { Qingtian) }\end{array}$ & English & Others \\
\hline You & & & & & \\
\hline Your father & & & & & \\
\hline Your mother & & & & & \\
\hline $\begin{array}{l}\text { Your brothers and } \\
\text { sisters }\end{array}$ & & & & & \\
\hline Your grandparents & & & & & \\
\hline Others & & & & & \\
\hline
\end{tabular}




\section{REFERENCES}

[1] Antonella, Sorace and Ludovica Serratrice. 2009. "Internal and external interfaces in bilingual language development: Beyond structural overlap". International Journal of Bilingualism, 13 (2): 195-210.

[2] Bernstein, B. 1973. Class, Codes and Control. London: Routledge \& Kegan Paul.

[3] Bybee, J. 2001. Phonology and Language Use. Cambridge: Cambridge University Press.

[4] Colectivo Ioé. 2005. "Inmigrantes Extranjeros en España: Reconfigurando la sociedad?" [Foreign Immigrants in Spain: Reconfiguring Society]. Panorama Social, 1: 32-47.

[5] Creswell. 2003. Research Design: Qualitative, Quantitative, and Mixed Methods Approaches. CA: Thousand Oaks.

[6] Crookes, G. and Schmidt, R. W. 1991. "Motivation: Reopening the Research Agenda". Language Learning 41 (4): 469-512.

[7] Dornyei, Z. 1990. "Conceptualising motivation in foreign language learning”. Language Learning, 40, 45-78.

[8] Dörnyei, Z., \& Skehan, P. 2003. "Individual Differences in Second Language Learning”. In C. Doughty \& M. Long (Eds.), The Handbook of Second Language Acquisition (pp. 589-630). Oxford: Blackwell.

[9] Dörnye, Z. 2007. Research Methods in Applied Linguistics: Quantitative, Qualitative, and Mixed Methodologies. Oxford: Oxford University Press.

[10] Ellis, N. 2002. "Frequency Effects in Language Processing: A Review for Theories of Implicit and Explicit Language Acquisition". Second Language Acquisition, 24: 143-188.

[11] Gardner, R. C., Lalonde, R. N. and Moorcroft, R. 1985. "The Role of Attitudes and Motivation in Second Language Learning: Correlational and Experimental Considerations". Language Learning: 35, 207-27.

[12] Ginsborg, J. 2006. "The Effects of Socio-economic Status on Children's Language". Acquisition and Use in Language and Social Disadvantage: Theory into Practice. Hoboken: John Wiley \& Sons, Ltd.

[13] Gottfried, A. E. 1985. "Academic Intrinsic Motivation in Elementary and Junior High School Students". Journal of Educational Psychology, 77 (6): 631-645.

[14] Gregory, E. 1993. "Sweet and Sour: Learning to Read in a British and Chinese School". English in Education, 3: 53-59.

[15] Gladys, Nieto. 2003. The Chinese in Spain. Oxford: Blackwell Publishing Ltd.

[16] Huang, Cheng. 2013. “语言传承与文化-第二代海外华人 语言调查” [Language and Cultural Heritage: The Second Generation Overseas Chinese Language Survey]. 文化月 刊 [Cultural Monthly] 10: 126-135.

[17] Hulstijn, Jan H. 2015. Language Proficiency in Native and
Non-native Speakers: Theory and Research. Amsterdam: John Benjamins Publishing Company.

[18] Itkonen, Esa. 1979. "Qualitative vs. Quantitative Analysis in Linguitics". In Evidence and Argumentation in Linguistics, edited by Perry, Thomas A. Berlin: De Gruyter.

[19] Kang, Xiaojuan. 2015. “海外华裔儿童华语学习、使用及 其家庭语言规划调查研究一以马来西亚 3 6 岁华裔儿童 家庭为例” [A Survey on the Language Use of Overseas Chinese Children and Family Language Plan: A Case Study of the Overseas Chinese Children aged 3-6 in Malaysia] 语言文字应用 [Applied Linguistics] (2): 10-18.

[20] Skehan, P. 1991. Individual Differences in Second Language Learning. Cambridge University Press.

[21] Labov, W. 1979. “The Logic of Nonstandard English". In V. Lee (Ed.), Language development. London: Croom Helm and Open University.

[22] Lambert, W. E. 1955. "Measurement of the linguistic dominance of bilinguals". Journal of Abnormal and Social Psychology, 50: 197-200.

[23] Li, Wei. 1994. Three generations, Two Languages, One Family: Language Choice and Language Shift in a Chinese Community in Britain. Philadelphia and Adelaide: Multilingual Matters.

[24] Lieven, E., \& Tomasello, M. 2008. "Children's First Language Acquisition from a Usage-based Perspective". In P. Robinson \& N. Ellis (Eds), Handbook of Cognitive Linguistics and Second Language Acquisition (pp. 168196). New York: Routledge.

[25] Lukmani, Y. M. 1972. "Motivation to Learn and Learning Proficiency". Language Learning, 22: 261-73.

[26] Norton Bonny. 1997. "Language, Identity, and the Ownership of English". TOSEL Quarterly, 31 (3): 409-429.

[27] Oller, D. K., B.Z. Pearson and A.B. Cobo-Lewis. 2007. "Profile Effects in Early Bilingual Language and Literacy." Applied Psycholinguistics 28 (2): 191-230.

[28] Peng, Lingling. 2006. “双语儿童语法的交互发展一特殊 疑问句建立过程的启示” [Interdependent Development in Bilingual Grammar Acquisition-What We Can Learn From a Case Study of Development of Wh-questions in an English-Cantonese Bilingual Child]. 外语学刊 [Foreign Language Research] 5: 81-86.

[29] Phakiti, 2015. "Quantitative Research and Analysis". In Research Methods in Applied Linguistics, A practical Resource. London: Bloomsbury.

[30] Ryan, Ellen Bouchard B. and Giles. Howard. 1982. Attitudes Toward Language Variation: Social and Applied Context. London: Edward Arnold Publishers.

[31] Sheng, Jing. 2012. “Chinese Parents' Concerns and Roles in Chinese - Origin Children's Chinese Maintenance and Bilingual Development". Journal of Yanbian University, 5: 95-131.

[32] Tomasello, M. and Todd, J. 1983. "Joint Attention and Lexical Acquisition Style". First Language, 4(12): 197-211.

[33] Wang, Danqing and Mary Clare Courtland. 2005. "Sino-Canadian Children's Chinese Literacy Development". 
Journal of Jiangsu Teachers University of Technology 11 (1): $66-72$.

[34] Wang, Wenyu. 2010. “双语儿童的语言能力发展: 实证研 究回顾” [Development of Bilingual Children's Language ability]. 外语研究 [Foreign Language Research] 3 (121): 52-60.

[35] Zhong hua Zi hai. [Zhonghua Chinese Dictionary]. (1994). Shanghai: Zhonghua Book Company.

[36] Zou, Jiayan and You, Rujie. 2001. 汉语与华人社会 [Chinese Language and Society]. Shanghai: Fudan University Press. 